\title{
Identification of a set of miRNAs differentially expressed in transiently TIA-depleted HeLa cells by genome-wide profiling
}

\author{
Carmen Sánchez-Jiménez ${ }^{1}$, Isabel Carrascoso ${ }^{1}$, Juan Barrero² and José M Izquierdo ${ }^{1 *}$
}

\begin{abstract}
Background: T-cell intracellular antigen (TIA) proteins function as regulators of cell homeostasis. These proteins control gene expression globally at multiple levels in response to dynamic regulatory changes and environmental stresses. Herein we identified a micro(mi)RNA signature associated to transiently TIA-depleted HeLa cells and analyzed the potential role of miRNAs combining genome-wide analysis data on mRNA and miRNA profiles.

Results: Using high-throughput miRNA expression profiling, transient depletion of TIA-proteins in HeLa cells was observed to promote significant and reproducible changes affecting to a pool of up-regulated miRNAs involving miR-30b-3p, miR125a-3p, miR-193a-5p, miR-197-3p, miR-203a, miR-210, miR-371-5p, miR-373-5p, miR-483-5p, miR-492, miR-498, miR-503-5p, miR-572, miR-586, miR-612, miR-615-3p, miR-623, miR-625-5p, miR-629-5p, miR-638, miR-658, miR-663a, miR-671-5p, miR-769-3p and miR-744-5p. Some up-regulated and unchanged miRNAs were validated and previous results confirmed by reverse transcription and real time PCR. By target prediction of the miRNAs and combined analysis of the genome-wide expression profiles identified in TIA-depleted HeLa cells, we detected connections between up-regulated miRNAs and potential target genes. Gene Ontology (GO) and Kyoto Encyclopedia of Genes and Genomes (KEGG) database analysis suggest that target genes are related with biological processes associated to the regulation of DNA-dependent transcription, signal transduction and multicellular organismal development as well as with the enrichment of pathways involved in cancer, focal adhesion, regulation of actin cytoskeleton, endocytosis and MAPK and Wnt signaling pathways, respectively. When the collection of experimentally defined differentially expressed genes in TIA-depleted HeLa cells was intersected with potential target genes only 7 out of 68 (10\%) up- and 71 out of 328 (22\%) down-regulated genes were shared. GO and KEGG database analyses showed that the enrichment categories of biological processes and cellular pathways were related with innate immune response, signal transduction, response to interleukin-1, glomerular basement membrane development as well as neuroactive ligand-receptor interaction, endocytosis, lysosomes and apoptosis, respectively.
\end{abstract}

Conclusion: All this considered, these observations suggest that individual miRNAs could act as potential mediators of the epigenetic switch linking transcriptomic dynamics and cell phenotypes mediated by TIA proteins.

Keywords: TIA1, TIAR, miRNAs, Gene regulatory networks

\footnotetext{
* Correspondence: jmizquierdo@cbm.uam.es

${ }^{1}$ Centro de Biología Molecular Severo Ochoa, Consejo Superior de Investigaciones Científicas, Universidad Autónoma de Madrid (CSIC/UAM), C/ Nicolás Cabrera 1, Cantoblanco, Madrid 28049, Spain

Full list of author information is available at the end of the article
} 


\section{Background}

Nowadays, the central dogma of Molecular Biology developed from classic research works aimed at determining the biology of prokaryotic organisms- is known to reflect only a part of the agenda containing the genetic information that gives rise to the complexity of eukaryotic organisms. The characterization of post-transcriptional events leading to the generation of multiple RNAs, proteins and functions from only one RNA precursor shows up the existence of multiple overlapping regulatory networks and mechanisms for the control of biological functions beyond transcriptional regulation. There is increasing evidence to support the idea that transcriptome and proteome regulation and heterogeneity are key stages to understand differences in the protein diversity observed in organisms of similar genetic complexity. It's therefore necessary to fully characterize the modulators linking and synchronizing multiple layers of gene expression regulation.

T-cell intracellular antigen 1 (TIA1) and TIA1 related/ like (TIAR/TIAL1) proteins are two DNA/RNA binding proteins that regulate many aspects of RNA metabolism at different levels. These multifunctional regulators can modulate: i) DNA-dependent transcription through its interaction with DNA and RNA polymerase II [1-4]; ii) alternative splicing of pre-mRNA through the selection of atypical $5^{\prime}$ spliced sites [5-8], and iii) stability and/or translation of eukaryotic mRNAs through the interaction with $5^{\prime}$ and/or $3^{\prime}$ untranslatable regions [9-16]. Some of these regulatory layers operate in the control of main biological programmes so as to maintain cellular homeostasis; this programmes include apoptosis, inflammation, cell responses to stress or viral infections ([10] and references included). Furthermore, mice lacking either TIA1 [16] or TIAR [17], as well as ectopically over-expressing TIAR [18], show higher rates of embryonic lethality.

MicroRNAs (miRNAs) are a class of 19-25 nt long non-coding RNAs that regulate post-transcriptionally gene expression by binding with partially complementary sequences on target mRNAs and inhibiting translation or affecting stability of these mRNAs [19]. Multiple lines of evidence indicate that they are key regulators of numerous critical functions in developmental, cell differentiation and disease processes, including tumorigenesis and cancer progression [19]. However, defining the place and function of miRNAs in complex regulatory networks is not straightforward. Systems' approaches such as the inference of a module network from expression data can help to achieve this goal [19].

We have previously described specific changes of transcriptomic dynamics associated to inflammation, angiogenesis, metabolism, and cell proliferation-related genes upon TIA1/TIAR-RNA interference-based silencing in HeLa cells [10]. In the present study, we test the hypothesis whether there are specific changes associated to the pattern of
miRNA expression which may interfere/modulate with target genes and, therefore, contribute to the phenotypes described in TIA-depleted HeLa cells. Herein, we identified a miRNA signature that is concomitant and coherent with biological processes and pathways associated to the phenotypes observed in HeLa cells lacking TIA proteins.

\section{Methods}

\section{Cell culture and RNA interference (RNAi)analysis}

HeLa cells were grown and transfected with $20 \mathrm{nM}$ of either a control siRNA (non-silencing siRNA duplex fluorescein labeled 27-6411-02FL from Gene Link) or two siRNAs against TIA1 (5'-AAGCTCTAATTCTGCAA CTCTTT-3'; 5'-AACAACTAA TGCGTCAGACTTTT-3') and TIAR (5'-AAGTCCTTATACTTCAGTTGTTC-3'; 5'AACCATGGAATCAACAAGGATTT- $3^{\prime}$ ) directed to the positions 59-81/647-669 and 65-87/971-993 to the coding regions of TIA 1 and TIAR mRNAs, respectively, as described previously $[7,10]$.

\section{Cell extract preparation, western blot analysis and RNA purification}

Whole-cell extracts were prepared by resuspensing the cells in lysis buffer (50 mM Tris- $\mathrm{HCl}, \mathrm{pH} 8.0,140 \mathrm{mM}$ $\mathrm{NaCl}, 1.5 \mathrm{mM} \mathrm{MgCl}_{2}, 0.5 \%$ Nonidet P-40 plus a mixture of protease inhibitors), freeze-thawing three times, and centrifugation at $10,000 \mathrm{rpm}$ for $5 \mathrm{~min}$. in a microfuge at $4^{\circ} \mathrm{C}$. Resulting supernatants were recovered and stored at $-70^{\circ} \mathrm{C}$ [10]. Immunoblots were carried out loading equal amounts of protein $(15 \mu \mathrm{g})$ on 10\% SDS-PAGE and using the following antibodies: anti-TIA1 and antiTIAR from Santa Cruz Biotechnology (CA, USA) and anti- $\alpha$-tubulin from Sigma (UK). RNA was extracted by using a miRVANA kit (Ambion, TX, USA) according to the manufacturer's protocol.

\section{MicroRNA expression profiling analysis}

The quality of the total RNA was verified by an Agilent 2100 Bioanalyzer profile. $2000 \mathrm{ng}$ total RNA from each sample was labeled with $\mathrm{Hy} 3^{\mathrm{TM}}$ or $\mathrm{Hy} 5^{\mathrm{TM}}$ fluorescent label, using the miRCURY LNA ${ }^{\mathrm{TM}}$ microRNA Labeling Kit $\mathrm{Hy} 3^{\mathrm{TM}} / \mathrm{Hy} 5^{\mathrm{TM}}$ (Exiqon, Denmark), following the procedure described by the manufacturer. $\mathrm{A} \mathrm{Hy}^{\mathrm{TM}}$ - and a $\mathrm{Hy}^{\mathrm{TM}}{ }^{\mathrm{T}}$-labeled RNA sample were mixed pair-wise and hybridized to the miRCURY LNA ${ }^{\mathrm{TM}}$ microRNA Array (Exiqon, Denmark), which contains capture probes targeting all microRNAs for human registered in the miRBASE version 9.1. The hybridization was performed according to the miRCURY LNA ${ }^{\mathrm{TM}}$ microRNA Array Instruction manual using a Tecan $\mathrm{HS} 4800^{\mathrm{TM}}$ hybridization station (Tecan, Austria). After hybridization the microarray slides were scanned and stored in an ozone free environment (ozone level below $2.0 \mathrm{ppb}$ ) in order to prevent potential bleaching of the fluorescent dyes. The miRCURY 
$\mathrm{LNA}^{\mathrm{TM}}$ microRNA Array slides were scanned using the Agilent G2565BA Microarray Scanner System (Agilent Technologies, Inc., USA) and the image analysis was carried out using the ImaGene ${ }^{\circledR} 7.0$ (miRCURY LNA ${ }^{\mathrm{TM}}$ microRNA Array Analysis Software, Exiqon, Denmark). The quantified signals were background corrected (local background subtraction) and normalized using the global Lowess (LOcally WEighted Scatterplot Smoothing) regression algorithm.

Local background was corrected by normexp method with an offset of 50. Background corrected intensities were transformed to log scale (base 2) and normalized by Lowess for each array [20]. Finally, to have similar intensity distribution across all arrays, Lowess-normalized-intensity values were scaled by adjusting their quantiles [21]. After data processing each probe was tested for changes in expression over replicates using an empirical Bayes moderated $t$ statistic [22]. To control the false discovery rate (FDR), P values were corrected using the method of Benjamini and Hochberg (1995) [23]. FIESTA viewer (http://bioinfogp.cnb.csic.es/tools/ FIESTA) was used to visualize all microarray results and to evaluate the numerical thresholds $(-2>$ fold change $>2$; FDR $<0.0001)$ applied for selecting differentially expressed genes [24].

The miRPlus sequences are licensed human sequences (Exiqon, Denmark). Some of them are already annotated in the miRBase database version 18. Microarray data discussed in this publication have been deposited in the NCBI Gene Expression Omnibus database (http://www. ncbi.nlm.nih.gov/geo/info/linking.html) and are accessible through the GEO Series accession number GSE41213.

\section{QPCR}

The method was optimized for microRNA, and reagents, primers, and probes were obtained from Applied Biosystems. Reverse transcriptase (RT) reactions and real-time PCR (PCR) were performed according to manufacturer protocols at the Genomic PCR Core Facility at Universidad Autónoma de Madrid in Madrid Scientific Park. Analyses were performed in two independent samples by triplicate, including no-template and RT-minus controls. U6 RNA and miR-200 expression were used as endogenous reference controls. Relative miRNA expression was calculated using the comparative cycle threshold method.

\section{Generation of miRNA targets dataset}

In silico targets predicted for each of the differentially expressed miRNAs by three different algorithms: TargetScan 5.2 ([25] and references included), PicTar-Vert ([26] and references included) and miRDB $[27,28]$ were downloaded using web-app miRBase [29] (http://www.mirbase. org). Given that each algorithm focus on different aspects of miRNA-mRNA pairing, and the lack of experimental validation of most miRNAs targets do not allow a false- positive elimination, we kept the datasets by considering the following score values: TargetScan 5.2 (aggregate PCT > 0.1), PicTar-Vert (PicTar score > 2) and miRBD (target score $>70$ ).

\section{Gene ontology, pathway and network analyses}

The Gene Ontology (GO) and Kyoto Encyclopedia of Genes and Genomes (KEGG) database analysis were conducted using software programmes provided by GenCodis3 (http://genecodis.cnb.csic.es) [30,31]. Networks and regulatory topologies of functional relationships between gene clusters were created using the CytoScape [32] (http://www. cytoscape.org).

\section{Results}

To analyze the putative role of TIA proteins in the control of gene expression on microRNAs, we transfected HeLa cells with double-stranded small interfering RNAs (siRNAs) targeting TIA1 and TIAR mRNAs or with control siRNA (C), as previously reported [10]. The effect of siRNAs on TIA1/TIAR expression was analyzed by Western blotting (Figure 1A). Upon TIA1/TIAR-RNA interference-based silencing, $80-90 \%$ and $70-80 \%$ depletions of TIA1 and TIAR proteins, respectively (Figure 1A) were achieved $72 \mathrm{~h}$ after transfection, thus in agreement with previous observations [10]. By contrast, $\alpha$-tubulin protein (Figure 1A) was used as control of siRNA specificity, and its expression level was not significantly affected by gene interference approach.

To test the microRNA (miRNA) expression profiles resulting from the reduction of TIA1 and TIAR protein levels, the differences in global miRNA expression patterns in control and TIA1/TIAR-depleted HeLa cells were determined by means of a miRCURY ${ }^{\mathrm{TM}}$ LNA Array with specific probes for simultaneous analysis of at least 600 different miRNAs. After having passed sample QC on the Bioanalyzer 2100 and RNA measurement on the Nanodrop instrument, the samples were labelled using the miR$\mathrm{CURY}^{\mathrm{TM}} \mathrm{Hy} 3^{\mathrm{TM}} / \mathrm{Hy} 5^{\mathrm{TM}}$ labelling kit and hybridized on the miRCURY $^{\mathrm{TM}}$ LNA Array (v.8.1) (Figure 1B). Analysis of the scanned slides showed that the labelling was successful as all capture probes for the control spike-in oligo nucleotides produced signals in the expected range. The quantified signals were normalized using the global Lowess (Locally WEighted Scatterplot Smoothing) regression algorithm, which we have found produces the best within-slide normalization to minimize the intensitydependent differences between the dyes (Figure 1B). The positive effect of this normalization is illustrated in 3 different plots for each experimental conditions analyzed (Additional file 1). It is interesting to note the high reproducibility of individual miRNA expression levels and their correlation across the different miRNA pools (Additional file 1). On the other hand, an appropriate statistical test analysis was made using a linear model (as implemented in 


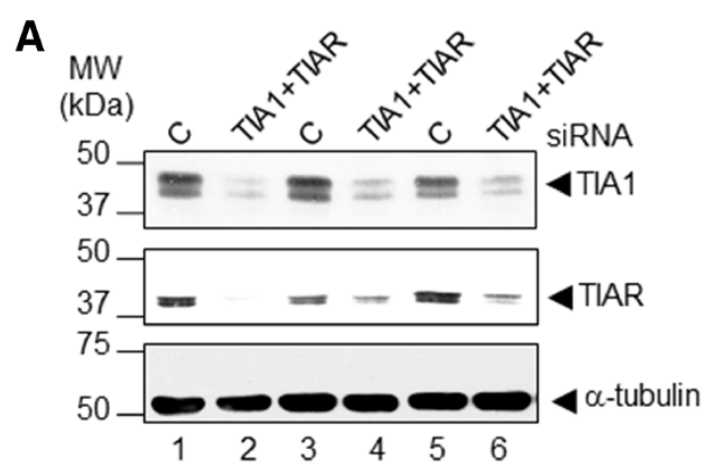

B
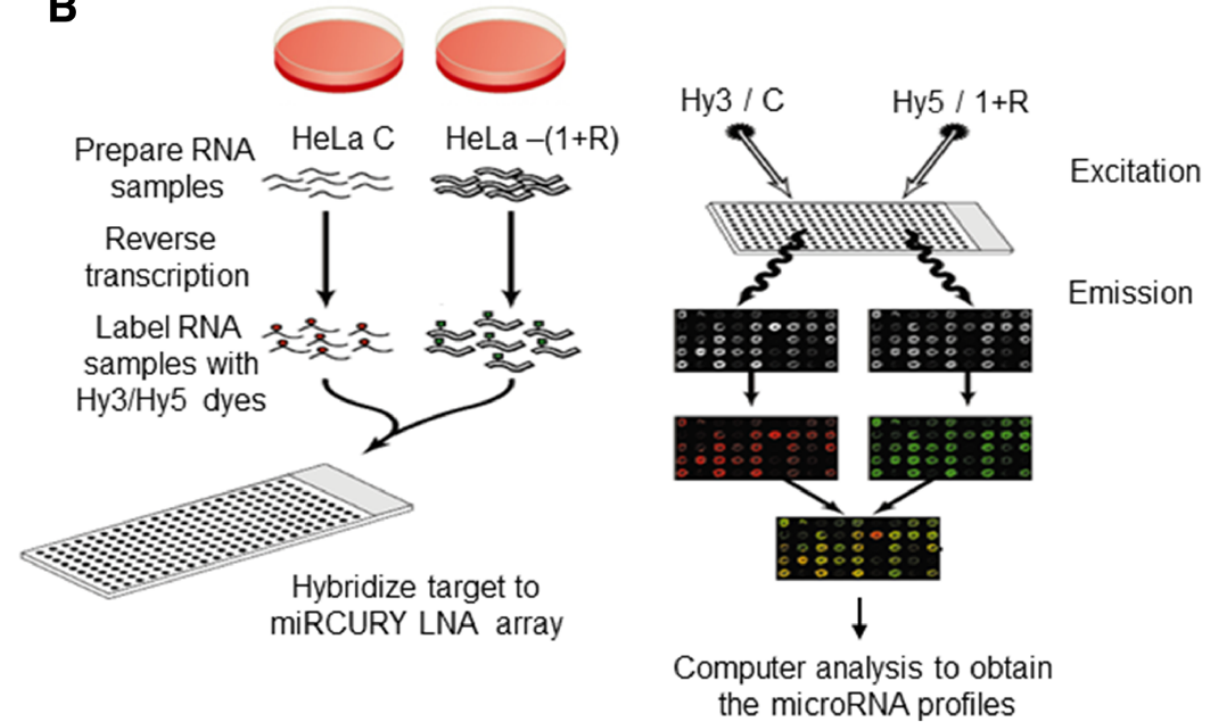

Figure 1 Small interfering RNA (siRNA)-mediated depletion of TIA proteins. (A) Western blot analysis of HeLa cell lysates prepared $72 \mathrm{~h}$ after transfection with siRNAs against control (C; lanes 1, 3 and 5) and TIA1 plus TIAR (lanes 2, 4 and 6). The blot was probed with antibodies against TIA1, TIAR, and a-tubulin proteins, as indicated. Molecular weight markers and the identities of protein bands are shown. (B) A schematic representation depicting the miRNA array strategy used in this study. The preparation of the RNA samples from control and TIA-depleted HeLa cells, labeling of above RNA samples with $\mathrm{Hy} 3$ and $\mathrm{Hy} 5$ dyes, hybridization and analyses of the resulting miRNA profiles are illustrated.

the limma R/Biocounductor package) to compare miRNA expression patterns for three two-color arrays performed from three independent biological replicates (Figure 1 and Additional file 1).

As shown in Table 1, depletion of TIA-proteins resulted in significantly altered miRNA expression profiling. The expression level of 29 out of 600 miRNAs was found to more than double when comparing channels Hy5 and Hy3. The genome-wide profiling analysis identified 17 miRNAs and 12 putative in-silico miRNAs (identified as miRPlus). These were the well-established miRNAs: miR-197-3p, miR-210, miR-373-5p, miR-492, miR-498, miR-503-5p, miR-572, miR-586, miR-612, miR-615-3p, miR-623, miR-625-5p, miR-638, miR-658, miR-663a, miR671-5p and miR-769-3p, which were differentially upregulated at least 2 -fold $(F D R<0.0001)$. The identified miRPlus sequences were in licensed human sequences; now a great number of these sequences have been annotated in the corresponding miRNA database. This information is available in Table 1. Regarding the differentially expressed miRPlus in our experimental conditions, an update of these miRPlus sequences in the miRBase 18 indicates that miRPlus-17836 is miR-30b-3p, miRPlus-17864 is miR-744-5p, miRPlus-17867 is miR-203a, miRPlus-17877 and miRPlus-17960 are miR-483-5p, miRPlus-17878 is miR-193a-5p, miRPlus-17942 is miR-125a-3p, miRPlus17950 is miR-371-5p and miRPlus-17961 is miR-629-5p (Table 1). The remaining miRPlus sequences have not been yet assigned to the putative specific miRNAs (Additional file 2).

To validate previous results on identified miRNAs and their relative expression levels, four up-regulated and two unchanged miRNAs were confirmed by TaqMan reverse transcription and polymerase chain reaction (QPCR) analyses. As shown in Figure 2, the results obtained by quantitative amplification were fully comparable and the relative 
Table 1 MicroRNA expression profiling in TIA-depleted HeLa cells

\begin{tabular}{|c|c|c|c|c|}
\hline Fold change & pval (LiMMA) & FDR (LiMMA) & miRNA ID & miRNA ID update \\
\hline 2.21 & 4.13E-06 & $8.26 \mathrm{E}-05$ & hsa-miR-197_MM2 & hsa-miR-197-3p \\
\hline 3.84 & 5.00E-07 & 1.70E-05 & hsa-miR-210 & - \\
\hline 2.3 & 4.84E-06 & $9.38 \mathrm{E}-05$ & hsa-miR-373* & hsa-miR-373-5p \\
\hline 2.75 & $3.78 \mathrm{E}-06$ & 7.77E-05 & hsa-miR-492 & - \\
\hline 2.79 & $1.38 \mathrm{E}-06$ & 3.55E-05 & hsa-miR-498 & - \\
\hline 2.5 & $5.22 \mathrm{E}-06$ & 9.89E-05 & hsa-miR-503 & hsa-miR-503-5p \\
\hline 4.29 & $1.00 \mathrm{E}-07$ & 4.05E-06 & hsa-miR-572 & - \\
\hline 3.78 & $3.60 \mathrm{E}-07$ & 1.27E-05 & hsa-miR-586 & - \\
\hline 2.24 & 5.01E-06 & 9.59E-05 & hsa-miR-612 & - \\
\hline 2.82 & 4.50E-06 & $8.81 \mathrm{E}-05$ & hsa-miR-615 & hsa-miR-615-3p \\
\hline 3.18 & $1.91 \mathrm{E}-06$ & 4.50E-05 & hsa-miR-623 & - \\
\hline 2.84 & 1.23E-06 & $3.31 \mathrm{E}-05$ & hsa-miR-625 & hsa-miR-625-5p \\
\hline 2.11 & 3.63E-06 & 7.54E-05 & hsa-miR-638 & - \\
\hline 2.44 & $1.64 \mathrm{E}-06$ & $3.96 \mathrm{E}-05$ & hsa-miR-658 & - \\
\hline 3.61 & $2.57 \mathrm{E}-06$ & 5.63E-05 & hsa-miR-663 & hsa-miR-663a \\
\hline 2.23 & 2.75E-06 & 5.96E-05 & hsa-miR-671 & hsa-miR-671-5p \\
\hline 3.65 & $3.18 \mathrm{E}-06$ & $6.70 \mathrm{E}-05$ & hsa-miR-769-3p & - \\
\hline 3.44 & 2.60E-07 & $9.88 \mathrm{E}-06$ & miRPlus_17832 & n.d. \\
\hline 2.73 & $9.60 \mathrm{E}-07$ & 2.77E-05 & miRPlus_17836 & hsa-miR-30b-3p \\
\hline 4.38 & 5.70E-07 & $1.91 \mathrm{E}-05$ & miRPlus_17856 & n.d. \\
\hline 3.34 & $2.26 \mathrm{E}-06$ & 5.13E-05 & miRPlus_17864 & hsa-miR-744-5p \\
\hline 2.5 & $2.91 \mathrm{E}-06$ & $6.23 \mathrm{E}-05$ & miRPlus_17867 & hsa-miR-203a \\
\hline 2.7 & 6.30E-07 & 2.04E-05 & miRPlus_17877/17960 & hsa-miR-483-5p \\
\hline 2.33 & 4.69E-06 & $9.13 \mathrm{E}-05$ & miRPlus_17878 & hsa-miR-193a-5p \\
\hline 2.84 & $1.87 \mathrm{E}-06$ & 4.43E-05 & miRPlus_17881 & n.d. \\
\hline 3.63 & $5.50 \mathrm{E}-07$ & $1.85 \mathrm{E}-05$ & miRPlus_17890 & n.d. \\
\hline 3.3 & $2.16 \mathrm{E}-06$ & 4.94E-05 & miRPlus_17942 & hsa-miR-125a-3p \\
\hline 2.15 & 2.85E-06 & $6.14 \mathrm{E}-05$ & miRPlus_17950 & hsa-miR-371-5p \\
\hline 2.6 & $1.34 \mathrm{E}-06$ & $3.45 E-05$ & miRPlus_17961 & hsa-miR-629-5p \\
\hline
\end{tabular}

miRNA cluster defining a signature of up-regulated miRNAs in TIA-depleted HeLa cells. The microarray data were analyzed by the limma R method. Fold is an average measure of the fold change in differential expression and the false discovery rate (FDR) indicates the expected percentage of false positives (FDR < 0.0001 ). miRNA ID update are miRNAs and miRPlus renamed in agreement with miRBase 18 database. n.d. means non-determined.

fold changes in miRNA expression were consistent with the data detected by hybridization in the corresponding microarrays (compare Table 1 and Figure 2).

As a first attempt to understand the relevance of 29 differentially up-regulated miRNAs, in silico methods for predicting human miRNA target genes were used (Figure 3). The potential target genes were identified by searching the TargetScan, PicTar and miRBD databases [25-28]. By comparing and selecting alone non-repeated target genes, 2683 miRNA target genes were identified (Additional file 3). All these potential target genes were tested using computer tool GeneCodis3 $[20,21]$ to elucidate the biological processes and cellular pathways assigned using Gene Ontology (GO) and Kyoto Encyclopedia of Genes and Genomes (KEGG) database analyses (Figure 3 and Additional file 3).
A total of 253 biological processes from GO database and 50 cellular pathways from KEGG categories were estimated with a significance hypergeometric test (corrected hypergeometric $\mathrm{p}$ value $<0.01$ ). Target genes corresponding to the biological processes from GO categories were mainly involved in regulation of DNA-dependent transcription, signal transduction, multicellular organismal development, positive/negative regulation of transcription from RNA polymerase II promoter, cell adhesion, transmembrane transport, apoptotic process and nervous system development (Table 2 and Additional file $3)$. In addition, target genes associated to the main biological pathways were also identified using KEGG database involving pathways in cancer, MAPK signalling pathway, focal adhesion, endocytosis, regulation of 


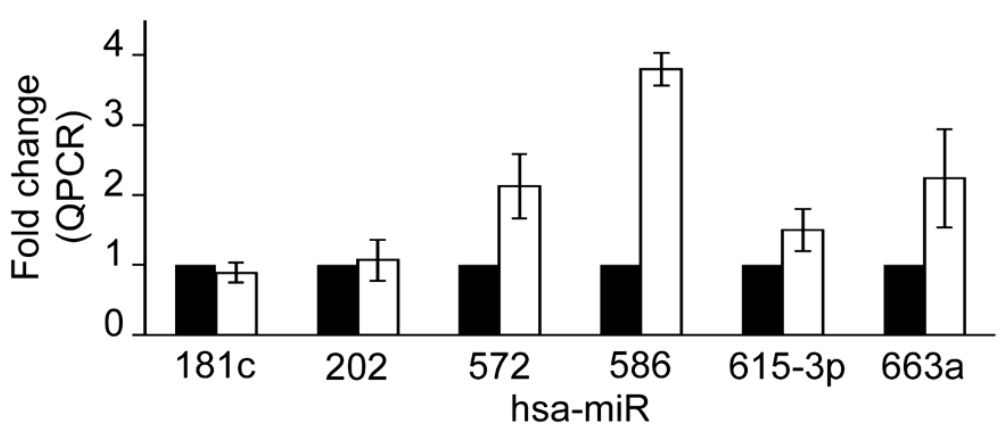

Figure 2 Validation of miRNA array-predicted changes by quantitative RT-PCR (QPCR). Quantitative miRNA expression analysis was carried out using TaqMan probes by QPCR. The represented values were normalized and expressed relative to control values (whose value was fixed arbitrarily to 1$)$ as ratios and are means $\pm S D(n=2)$.

actin cytoskeleton, Wnt signalling pathway, neuroactive ligand-receptor interaction, glutamatergic synapse, ubiquitin mediated proteolysis and tuberculosis (Table 2 and Additional file 3). Collectively, these results suggest that TIA-protein depletion promotes the induction of a miRNA signature which may directly and indirectly contribute to the establishment of the observed cellular phenotypes in TIA-deficient HeLa cells [10].

On the other hand, the collection of differentially expressed genes previously identified by expression microarray Human

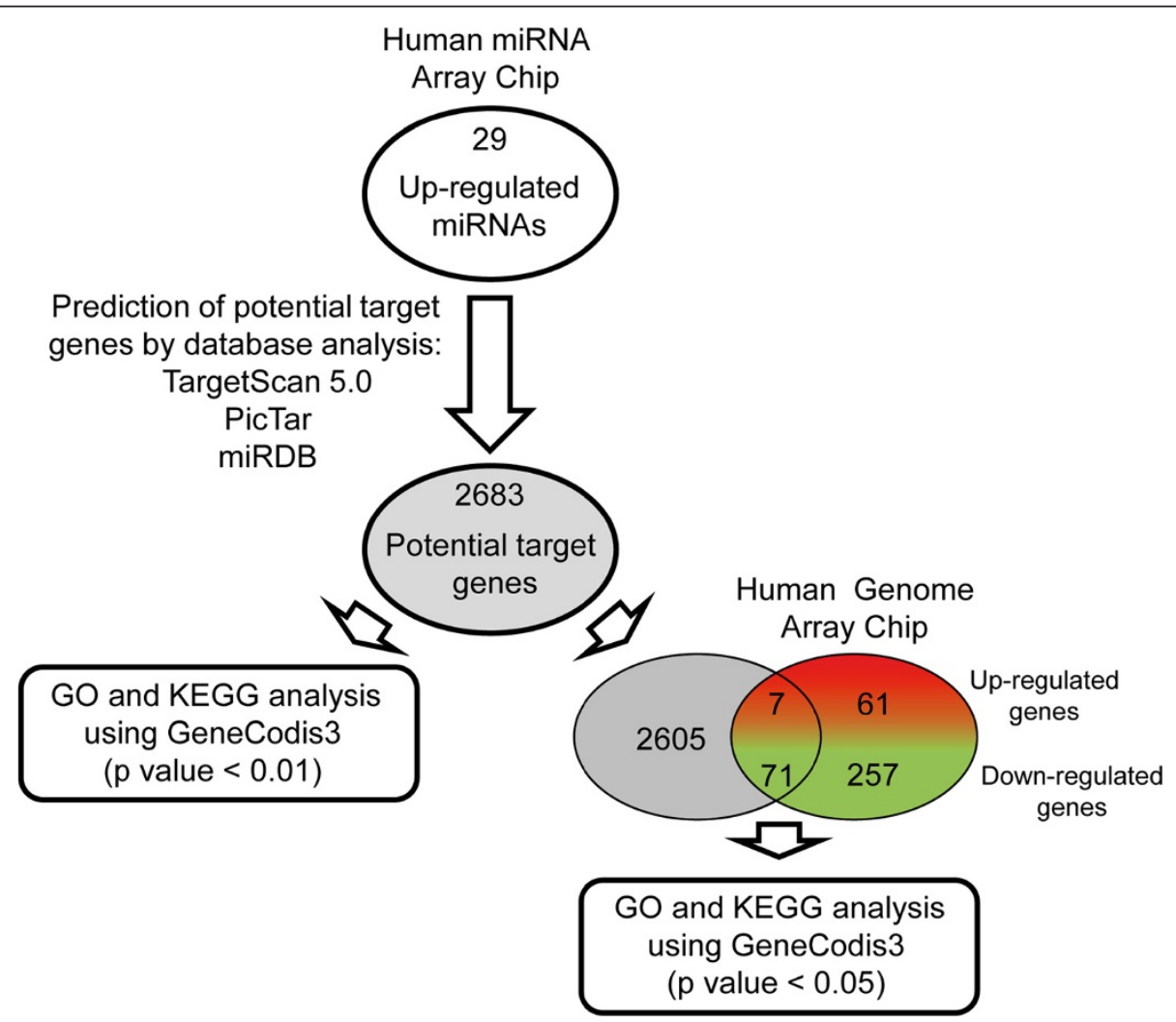

Figure 3 Prediction of potential and experimental target genes associated with up-regulated miRNAs in TIA-depleted HeLa cells. Integrative analyses of potential target genes and miRNAs regulated in TIA-depleted HeLa cells using TargetScan 5.2, PicTar-Vert and miRDB software tools (see corresponding section in Methods). Diagrams depicting the number of potential target genes and up-regulated miRNAs (Additional file 3) by TIA silencing are shown. Venn diagram depicting the numbers of genes that were intersected among putative target genes (highlighted in gray) associated to miRNAs and experimentally defined differentially expressed genes (see additional data files in [10]) in HeLa cells lacking TIA proteins. The Gene Ontology (GO) and Kyoto Encyclopedia of Genes and Genomes (KEGG) database analyses were conducted using software programmes provided by GenCodis3. 
Table 2 Top ten biological processes and pathways associated to up-regulated miRNAs in TIA-depleted HeLa cells

\begin{tabular}{|c|c|c|c|}
\hline Term & Description & Number of genes & p-value \\
\hline \multicolumn{4}{|l|}{ GO } \\
\hline GO:0006355 & Regulation of transcription, DNA-dependent & 269 & $2.49 \mathrm{E}-33$ \\
\hline GO:0007165 & Signal transduction & 188 & $1.00 \mathrm{E}-18$ \\
\hline GO:0007275 & Multicellular organismal development & 151 & 5.17E14 \\
\hline GO:0045944 & Positive regulation of transcription from RNA pol II promoter & 124 & 2.69E-21 \\
\hline GO:0007155 & Cell adhesion & 103 & 4.06E-12 \\
\hline GO:0055085 & Transmembrane transport & 102 & $5.89 \mathrm{E}-08$ \\
\hline GO:0045893 & Positive regulation of transcription, DNA-dependent & 96 & $5.89 \mathrm{E}-14$ \\
\hline GO:0006915 & Apoptotic process & 96 & 4.13E-07 \\
\hline GO:0000122 & Negative regulation of transcription from RNA pol II promoter & 95 & 4.66E-17 \\
\hline GO:0007399 & Nervous system development & 93 & $1.98 \mathrm{E}-16$ \\
\hline \multicolumn{4}{|l|}{ KEGG } \\
\hline Kegg:05200 & Pathways in cancer & 68 & $5.72 \mathrm{E}-11$ \\
\hline Kegg:04010 & MAPK signaling pathway & 58 & $3.68 \mathrm{E}-08$ \\
\hline Kegg:04510 & Focal adhesion & 49 & 2.75E-08 \\
\hline Kegg:04144 & Endocytosis & 46 & 7.60E-07 \\
\hline Kegg:04810 & Regulation of actin cytoskeleton & 44 & $1.48 \mathrm{E}-04$ \\
\hline Kegg:04310 & Wnt signaling pathway & 37 & $3.88 \mathrm{E}-05$ \\
\hline Kegg:04080 & Neuroactive ligand-receptor interaction & 35 & 9.43E-04 \\
\hline Kegg:04724 & Glutamatergic synapse & 32 & 2.34E04 \\
\hline Kegg:04120 & Ubiquitin mediated proteolysis & 31 & $5.96 \mathrm{E}-03$ \\
\hline Kegg:05152 & Tuberculosis & 28 & 1.17E-04 \\
\hline
\end{tabular}

Gene Ontology (GO) and Kyoto Encyclopedia of Genes and Genomes (KEGG) databases analysis were carried out using GeneCodis3 software. The categories were ranked on their numbers of associated genes and the ten with the highest number of genes are shown.

Genome U133 Plus 2.0 (Affymetrix) in TIA-depleted HeLa cells [10] were intersected with potential target genes identified using in silico target prediction tools. The results show that only 7 out of 68 (10\%) up- and 71 out of $328(22 \%)$ down-regulated genes were shared (Figure 3 and Table 3). GO and KEGG database analyses were independently performed for up- and down-regulated genes with GeneCodis3 software. The results suggest that the enrichment functional categories $(\mathrm{p}<0.05)$ are related with signal transduction, innate immune response and response to interleukin-1 for up-regulated genes and glomerular basement membrane development for down-regulated genes. Further, cellular pathways of neuroactive lingand-receptor interaction and apoptosis were associated to up-regulated genes, whereas endocytosis and lysosomes were linked to down-regulated genes (Table 4). Taken together, these results suggest that at least a fraction (40\%) of the up-regulated miRNAs (12 out of 30) could be contributing to the establishment of differential expression profiles associated to the HeLa cells lacking TIA proteins.

Based on above observations an interesting question emerges: why should many specific genes be up- or downregulated by induced miRNAs in TIA-depleted HeLa cells? A simple answer to this question might be that these
mRNAs or their precursors (pre-mRNAs) are targeted by TIA proteins through one or multiple layers to exert the control of their gene expression; thus, these regulators can act as multifunctional RNA binding proteins (see references included in Background). To approach this issue, the experimental profiles of the binding patterns of TIA proteins (i.e., the RNA map corresponding to TIA proteins) at the up- or down-regulated pre-mRNAs (Figure 4 and Table 3) were examined using the iCLIP database of TIA proteins kindly provided by Jernej Ule's laboratory [8]. For example, as shown in Figure 4 and in Table 3, the premRNAs analyzed show multiple sequence sites located across the full-length pre-mRNAs, both exons and introns, and which we have classified as genes with either low $(+)$, medium $(++)$ or high $(+++)$ density of TIA binding sites. The greatest relevance of this observation is the fact that the density of binding sites on these pre-mRNAs is found in both up- and down-regulated genes and located with frequency on the last exons of these pre-mRNAs and particularly on the sequences located at the $3^{\prime}$ untranslated regions of the mature mRNAs. In this regard, it is reasonable to think that the existence of a feedback loop that represses the expression of many genes, which could be activated in the absence of TIA proteins, for example at 
Table 3 Intersection between potential and experimentally defined target genes related to miRNAs in TIA-depleted HeLa cells

\begin{tabular}{|c|c|c|c|}
\hline Gene symbol & Description & Associated miRNA & TIA-iCLIP \\
\hline \multicolumn{4}{|c|}{ Up-regulated genes } \\
\hline CNR1 & Cannabinoid receptor 1 (brain) & miR-30b-3p & + \\
\hline EIF4A2 & Eukaryotic translation initiation factor 4A, isoform 2 & miR-586 & +++ \\
\hline EREG & Epiregulin & miR-586 & + \\
\hline F2RL2 & Coagulation factor II (thrombin) receptor-like 2 & miR-30b-3p & + \\
\hline IL1R1 & Interleukin 1 receptor, type I & miR-498 & ++ \\
\hline IRAK2 & Interleukin-1 receptor-associated kinase 2 & miR-503-5p & ++ \\
\hline SELI & Selenoprotein I & miR-197-3p & ++ \\
\hline \multicolumn{4}{|c|}{$\begin{array}{l}\text { Down-regulated } \\
\text { genes }\end{array}$} \\
\hline ACADSB & Acyl-Coenzyme A dehydrogenase, short/branched chain & miR-203 & ++ \\
\hline ACOX1 & Acyl-Coenzyme A oxidase 1, palmitoyl & miR-373-5p & ++ \\
\hline ALS2CR4 & Amyotrophic lateral sclerosis 2 (juvenile) chromosome region, candidate 4 & miR-203 & +++ \\
\hline ANKH & Ankylosis, progressive homolog (mouse) & miR-203 & +++ \\
\hline AP1S2 & Adaptor-related protein complex 1 , sigma 2 subunit & miR-203 & ++ \\
\hline AP2B1 & Adaptor-related protein complex 2 , beta 1 subunit & miR-203 & +++ \\
\hline APPBP2 & Amyloid beta precursor protein (cytoplasmic tail) binding protein 2 & miR-612 & ++ \\
\hline BBS1 & Bardet-Biedl syndrome 1 & miR-612 & + \\
\hline BRIP1 & BRCA1 interacting protein C-terminal helicase 1 & miR-373-5p & + \\
\hline C16orf72 & Chromosome 16 open reading frame 72 & miR-671-5p & +++ \\
\hline C18orf54 & Chromosome 18 open reading frame 54 & miR-625-5p & ++ \\
\hline C1orf96 & Chromosome 1 open reading frame 96 & $\operatorname{miR}-373-5 p$ & ++ \\
\hline C20orf108 & Chromosome 20 open reading frame 108 & miR-30b-3p & + \\
\hline CCDC50 & Coiled-coil domain containing 50 & miR-203 & + \\
\hline CENPH & Centromere protein $\mathrm{H}$ & miR-612 & + \\
\hline CLCC1 & Chloride channel CLIC-like 1 & miR-373-5p and 30b-3p & ++ \\
\hline COL4A4 & Collagen, type IV, alpha 4 & miR-203 & +++ \\
\hline CTDSPL2 & $\begin{array}{l}\text { CTD (carboxy-terminal domain, RNA polymerase II, polypeptide A) small phosphatase } \\
\text { like } 2\end{array}$ & miR-203 & +++ \\
\hline CTSC & Cathepsin C & miR-203 & ++ \\
\hline DAB2 & Disabled homolog 2, mitogen-responsive phosphoprotein (Drosophila) & miR-203 & +++ \\
\hline DDIT4 & DNA-damage-inducible transcript 4 & miR-30b-3p & ++ \\
\hline EEF1A1 & Eukaryotic translation elongation factor 1 alpha 1 & $\operatorname{miR}-373-5 p$ & + \\
\hline EIF4EBP2 & Eukaryotic translation initiation factor $4 \mathrm{E}$ binding protein 2 & $\operatorname{miR}-373-5 p$ & ++ \\
\hline ELMOD2 & ELMO/CED-12 domain containing 2 & miR-30b-3p & ++ \\
\hline EPHA7 & EPH receptor A7 & miR-503-5p & +++ \\
\hline FAM129A & Family with sequence similarity 129 , member A & miR-373-5p and 586 & ++ \\
\hline FBXO9 & F-box protein 9 & miR-203 & ++ \\
\hline IQCE & IQ motif containing $\mathrm{E}$ & miT-483-5p & + \\
\hline KCTD12 & Potassium channel tetramerisation domain containing 12 & miR-373-5p and 586 & + \\
\hline KLF9 & Kruppel-like factor 9 & miR-373-5p & ++ \\
\hline KRIT1 & KRIT1, ankyrin repeat containing & miR-373-5p & + \\
\hline LAMP2 & Lysosomal-associated membrane protein 2 & miR-373-5p & ++ \\
\hline MCM4 & Minichromosome maintenance complex component 4 & miR-373-5p & ++ \\
\hline
\end{tabular}


Table 3 Intersection between potential and experimentally defined target genes related to miRNAs in TIA-depleted HeLa cells (Continued)

\begin{tabular}{|c|c|c|c|}
\hline MECP2 & Methyl CpG binding protein 2 (Rett syndrome) & miR-203 & + \\
\hline MIB1 & Mindbomb homolog 1 (Drosophila) & $\begin{array}{l}\operatorname{miR}-373-5 p, 503 \text { and } \\
203\end{array}$ & ++ \\
\hline MOBKL2B & MOB1, Mps One Binder kinase activator-like 2B (yeast) & miR-503-5p and 203 & +++ \\
\hline MTAP & Methylthioadenosine phosphorylase & miR-125a-3p & ++ \\
\hline MTHFD2L & Methylenetetrahydrofolate dehydrogenase (NADP+ dependent) 2-like & miR-373-5p & ++ \\
\hline NAV1 & Neuron navigator 1 & miR-503-5p & ++ \\
\hline NDRG3 & NDRG family member 3 & miR-203 & ++ \\
\hline NDST1 & N-deacetylase/N-sulfotransferase (heparan glucosaminyl) 1 & miR-30b-3p & + \\
\hline NHLRC2 & NHL repeat containing 2 & $\operatorname{miR}-373-5 p$ & ++ \\
\hline NID1 & Nidogen 1 & miR-30b-3p & ++ \\
\hline PAWR & PRKC, apoptosis, WT1, regulator & miR-30b-3p & +++ \\
\hline PCGF6 & Polycomb group ring finger 6 & miR-203 & + \\
\hline PDE1A & Phosphodiesterase 1A, calmodulin-dependent & $\operatorname{miR}-373-5 p$ & +++ \\
\hline PGM2 & Phosphoglucomutase 2 & miR-498 & +++ \\
\hline PLD1 & Phospholipase D1, phosphatidylcholine-specific & miR-203 & +++ \\
\hline RAB22A & RAB22A, member RAS oncogene family & miR-498 & ++ \\
\hline RBM8A & RNA binding motif protein $8 \mathrm{~A}$ & $\operatorname{miR}-373-5 p$ & + \\
\hline RECK & Reversion-inducing-cysteine-rich protein with kazal motifs & miR-503-5p & ++ \\
\hline RGC32 & Regulator of cell cycle & miR-30b-5p & ++ \\
\hline SFPQ & $\begin{array}{l}\text { Splicing factor proline/glutamine-rich (polypyrimidine tract binding protein } \\
\text { associated) }\end{array}$ & miR-586 & ++ \\
\hline SGPL1 & Sphingosine-1-phosphate lyase 1 & $\operatorname{miR}-373-5 p$ & ++ \\
\hline SLC12A2 & Solute carrier family 12 (sodium/potassium/chloride transporters), member 2 & $\begin{array}{l}\operatorname{miR}-503-5 p, 586 \text { and } \\
203\end{array}$ & + \\
\hline SLC35B3 & Solute carrier family 35 , member B3 & miR-203 & ++ \\
\hline SNAPC3 & Small nuclear RNA activating complex, polypeptide 3,50kDa & miR-373-5p and 671 & +++ \\
\hline STXBP4 & Syntaxin binding protein 4 & $\operatorname{miR}-625-5 p$ & + \\
\hline SUDS3 & Suppressor of defective silencing 3 homolog (S. cerevisiae) & miR-203 & +++ \\
\hline SYNC1 & Syncoilin, intermediate filament 1 & miR-203 & ++ \\
\hline TFDP2 & Transcription factor Dp-2 (E2F dimerization partner 2) & miR-30b-3p and 203 & +++ \\
\hline TIA1 & TIA1 cytotoxic granule-associated RNA binding protein & miR-30b3p & +++ \\
\hline TNFRSF19 & Tumor necrosis factor receptor superfamily, member 19 & miR-125a-3p & ++ \\
\hline TNRC6B & Trinucleotide repeat containing 6B & $\begin{array}{l}\text { miR-503-5p, } 586 \text { and } \\
203\end{array}$ & ++ \\
\hline TSEN2 & tRNA splicing endonuclease 2 homolog (S. cerevisiae) & miR-197-3p & + \\
\hline VAMP1 & Vesicle-associated membrane protein 1 (synaptobrevin 1) & miR-203 & ++ \\
\hline VGLL3 & Vestigial like 3 (Drosophila) & $\operatorname{miR}-373-5 p$ & ++ \\
\hline VPS13A & Vacuolar protein sorting 13 homolog A (S. cerevisiae) & miR-586 & ++ \\
\hline WDFY3 & WD repeat and FYVE domain containing 3 & miR-203 & + \\
\hline ZBTB44 & Zinc finger and BTB domain containing 44 & miR-203 & ++ \\
\hline ZNF169 & Zinc finger protein 169 & miR-125a-3p & ++ \\
\hline
\end{tabular}

Gene cluster defining a molecular signature of up- (highlighted in red in Figure 3) and down-regulated (highlighted in green in Figure 3) genes linked to upregulated miRNAs in TIA-depleted HeLa cells. Gene symbol, gene title as description and associated miRNAs are indicated. Estimation of the density of binding sites of TIA proteins on up- and down-regulated target genes by iCLIP analysis is shown. The relative quantification estimated as low (+), medium (++) and high $(+++)$ density is indicated. 
Table 4 Biological processes and pathways linked to experimentally defined and differentially expressed genes in TIAdepleted HeLa cells

\begin{tabular}{|c|c|c|c|c|}
\hline Categories enriched in & Description & Number of genes & Gene symbol & p-value \\
\hline \multicolumn{5}{|l|}{ Up-regulated genes } \\
\hline \multicolumn{5}{|l|}{ GO term } \\
\hline GO:0070555 & Response to interleukin-1 & 2 & IL1R1, IRAK2 & $6.21 \mathrm{E}-04$ \\
\hline GO:0045087 & Innate immune response & 2 & IL1R1, IRAK2 & $6,88 \mathrm{E}-03$ \\
\hline GO:0007165 & Signal transduction & 2 & IL1R1, IRAK2 & $2,88 \mathrm{E}-02$ \\
\hline \multicolumn{5}{|l|}{ KEGG term } \\
\hline Kegg:04080 & Neuroactive ligand-receptor interaction & 2 & CNR1, F2RL2 & $6.88 \mathrm{E}-03$ \\
\hline Kegg:04210 & Apoptosis & 2 & IL1R1, IRAK2 & $1.43 \mathrm{E}-03$ \\
\hline \multicolumn{5}{|l|}{ Down-regulated genes } \\
\hline \multicolumn{5}{|l|}{ GO term } \\
\hline GO:0032836 & Glomerular basement membrane development & 2 & COL4A4, NID1 & 1.09E-02 \\
\hline \multicolumn{5}{|l|}{ KEGG term } \\
\hline Kegg:04144 & Endocytosis & 4 & RAB22A, AP2B1, DAB2, PLD1 & $3.23 \mathrm{E}-02$ \\
\hline Kegg:04142 & Lysosome & 3 & CTSC, AP1S2, LAMP2 & 4.77E-02 \\
\hline
\end{tabular}

Gene Ontology (GO) and Kyoto Encyclopedia of Genes and Genomes (KEGG) databases analysis were carried out using GeneCodis3 software.

the post-transcriptional levels (i.e. mRNA stability or translational activation), to dampen its expression in order to promote or counteract the cellular phenotypes associated to the absence of the TIA proteins.

During the last decade, much progress has been made in the understanding of network topology and the relevance and properties of its basic modules. In this study, we analyze and assess module networks inferred from both miRNAs and gene expression data using a bioinformatic tool as CytoScape [32]. By matching expressed miRNAs and experimentally defined up- and downregulated genes in TIA-depleted HeLa cells, a putative regulatory network of TIA-associated genes and miRNAs was constructed. Based on the number of potential gene interactions with single miRNAs, both up- and downexpressed genes regulating TIA-mediated differential expression were connected (Figure 5). This network draws a cellular scenario where the reduction of TIA proteins could lead to molecular responses mediated by individual miRNAs. Such a computational approach, starting from expression data alone, can be helpful in the future process of identification of the function of these miRNAs by suggesting modules of co-expressed genes in which they could play a regulatory role.

\section{Discussion}

Current data suggest that a significant portion of the information containing the human genome is regulated by miRNAs. These small RNAs recognize and regulate target genes. In this regard, more than $60 \%$ of proteincoding genes are predicted in silico as targets, based on conserved base-pairing between the $3^{\prime}$ - and $5^{\prime}$-untranslated regions (UTR) of the mRNA and the seed sequence of the miRNAs [33] without considering putative target on coding sequences. At present, near to 2,000 miRNAs have been identified in the human genome and about $20-30 \%$ of human genes are controlled by one or more miRNAs [33-36]. Multiple lines of evidence indicate that they are key regulators of numerous critical functions in development and disease, including cancer. Many of them have been reported to have molecular features and act either as tumour suppressors or oncogenes [33-35]. The changes in miRNA signature identified in this study might directly and indirectly function as encouraging/counteracting mechanism of biological processes and cellular pathways to promote/attenuate the inflammatory, angiogenic and proliferative responses linked to TIA-depleted HeLa cells [10].

Given that many target genes associated with the identified up-regulated miRNAs are down-regulated (Table 3) in TIA-depleted HeLa cells [10], from a mechanistic viewpoint our results indicate that mRNA abundance in most targeted genes was somewhat affected by miRNAs, thus suggesting that, for a substantial number of genes regulated by TIA-protein absence, destabilization of mRNA may be the main mechanism of protein repression by these miRNA-mediated regulators. This observation agrees with a recent study, suggesting that mammalian miRNAs predominantly reduce target mRNA levels [34]. However, some miRNAs such as miR-744 enhances cyclin B1 mRNA expression through a novel mechanism. miRNA positivelyregulates gene expression by targeting promoter elements; this phenomenon is known as RNA activation [37]. In this 


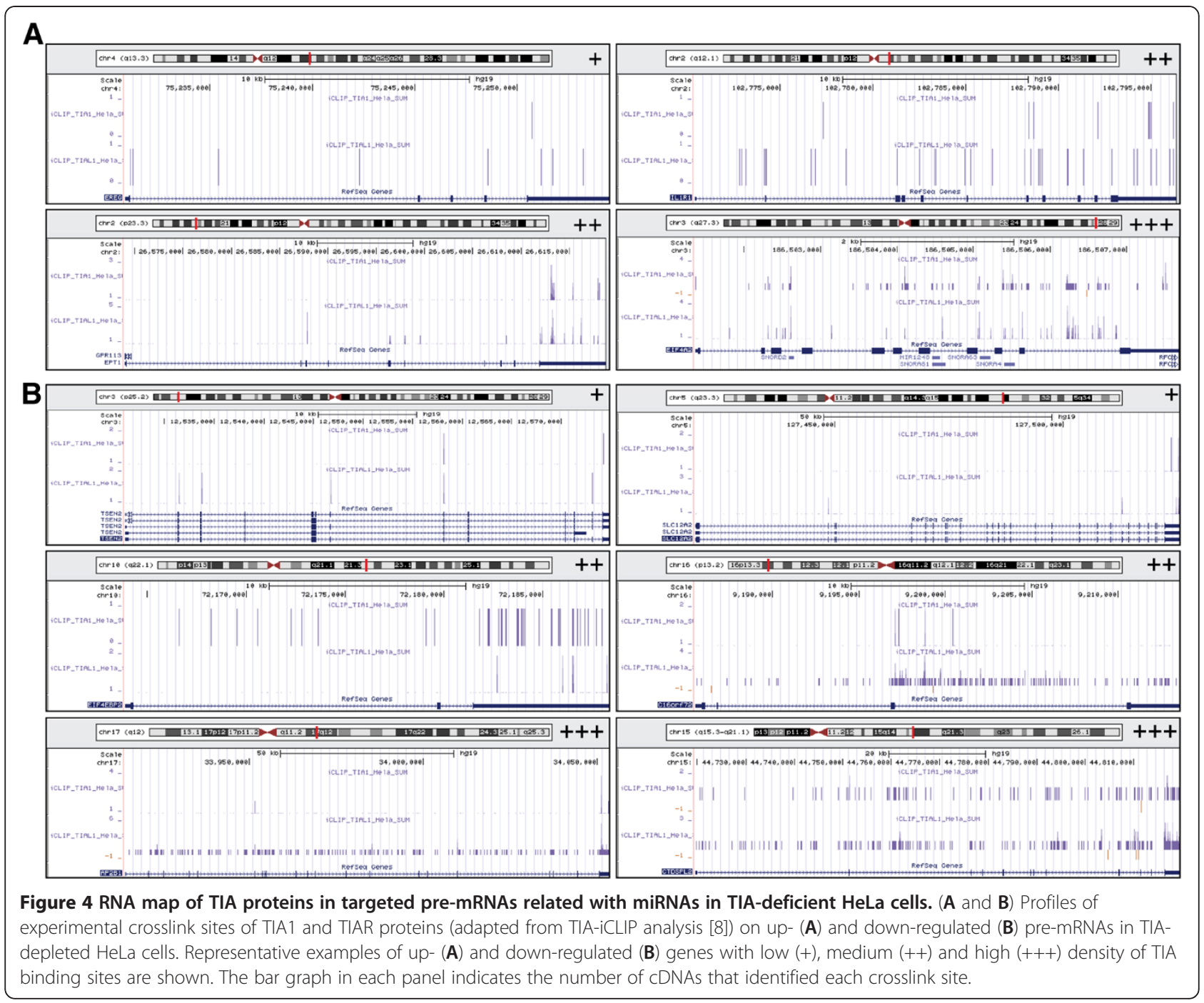

regard, it is reasonable to think that this mechanism could be operating in the up-regulation observed for seven target genes associated with the up-regulated miRNAs (Table 3). Furthermore, miRNAs do not only regulate the expression of protein-encoding genes but also other miRNAs: for instance, let-7a controls the expression of important epigenetic regulators, including epigenetic miRNA regulatory circuits, and organizes the whole gene expression profile [38]. On the other hand, there are miRNA-target interactions that involve multiple sites for a given target and confer much stronger repression. More often, different miRNAs work together to co-target a given mRNA, therefore their combined repressive effect greatly exceeds the individual contributions [34-36]. Both regulatory situations are observed in the down-regulated genes associated to up-regulated miRNAs in TIA-depleted HeLa cells (Table 3 ). This suggests that clusters of miRNAs can play a more prominent role than only reinforcing the expression patterns dictated by transcriptome dynamics. The existence of interactions among these regulators and the interactions between their regulatees suggests that these miRNAs generate networks that modulate antagonistic cellular responses, such as apoptosis or cell proliferation induction and/or repression. Our set of data indicates that the action of miRNAs could potentially be another important mechanism in the regulation of gene expression and some gene regulatory networks mediated by TIA proteins. These observations thus suggest the existence of feedback mechanisms that promote miRNA expression, which might therefore contribute to dampen the phenotypes observed in TIA-lacking HeLa cells. A type 2 incoherent feedforward loop [39] may contribute to the repression model between TIA proteins, target genes and associated miRNAs. This feedforward loop could reinforce the functional role of TIA proteins as repressors of inflammatory, angiogenic, and proliferative responses (Figure 6). 


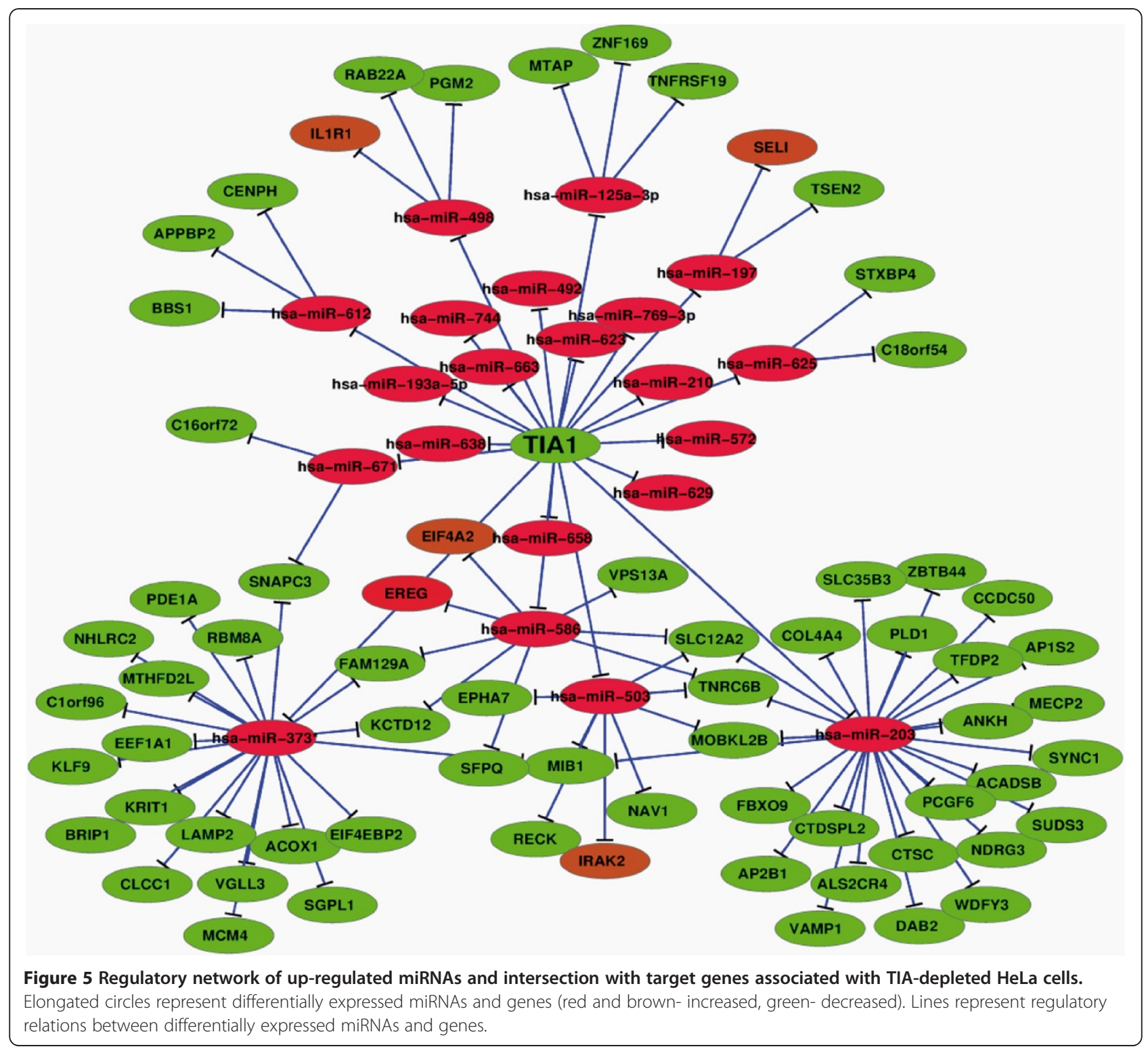

Regarding some miRNAs identified in this study, these could be related to miRNA-mediated gene expression fluctuations and, more faithfully, to signal outcomes in the context of specific regulatory networks. This suggest that miRNAs can strenghten transcriptome patterns by buffering the deleterious effects of some network states linked to random fluctuations in gene expression program, in agreement with previous findings [25]. Since little experimental information is available on potential target genes and miRNA cluster identified in our study and we have not experimentally carried out analysis of gain- and lossof function, we used experimental data on miRNA function to understand the potential implication and relevance of these miRNAs in the development and progression of (patho)-physiological conditions. For example, miRNA- 30b has been implicated in angiogenesis [40], TRAILinduced apoptosis in glioma cells [41] and oral squamous cell cancers [42]. miR-193a-5p targets YY1-APC regulatory axis in human endometrioid endometrial adenocarcinoma [43]. miR-203 participates in a regulatory network that modulates epithelial to mesenchymal transition [44] as well as to promote suppression immune [45]. miR-210 is induced under hypoxia and works as a iron sensor to stimulate cell proliferation and promote cell survival in the hypoxic region within tumor [46-48]. Further, this miRNA modulates the mitochondrial functioning and metabolism [49,50], represses FGFRL1 and E2F3 expression, which inhibits cell apoptosis in hypoxia response [51,52], predicts poor survival in patients with breast cancer [53] and activates notch signalling pathway in 


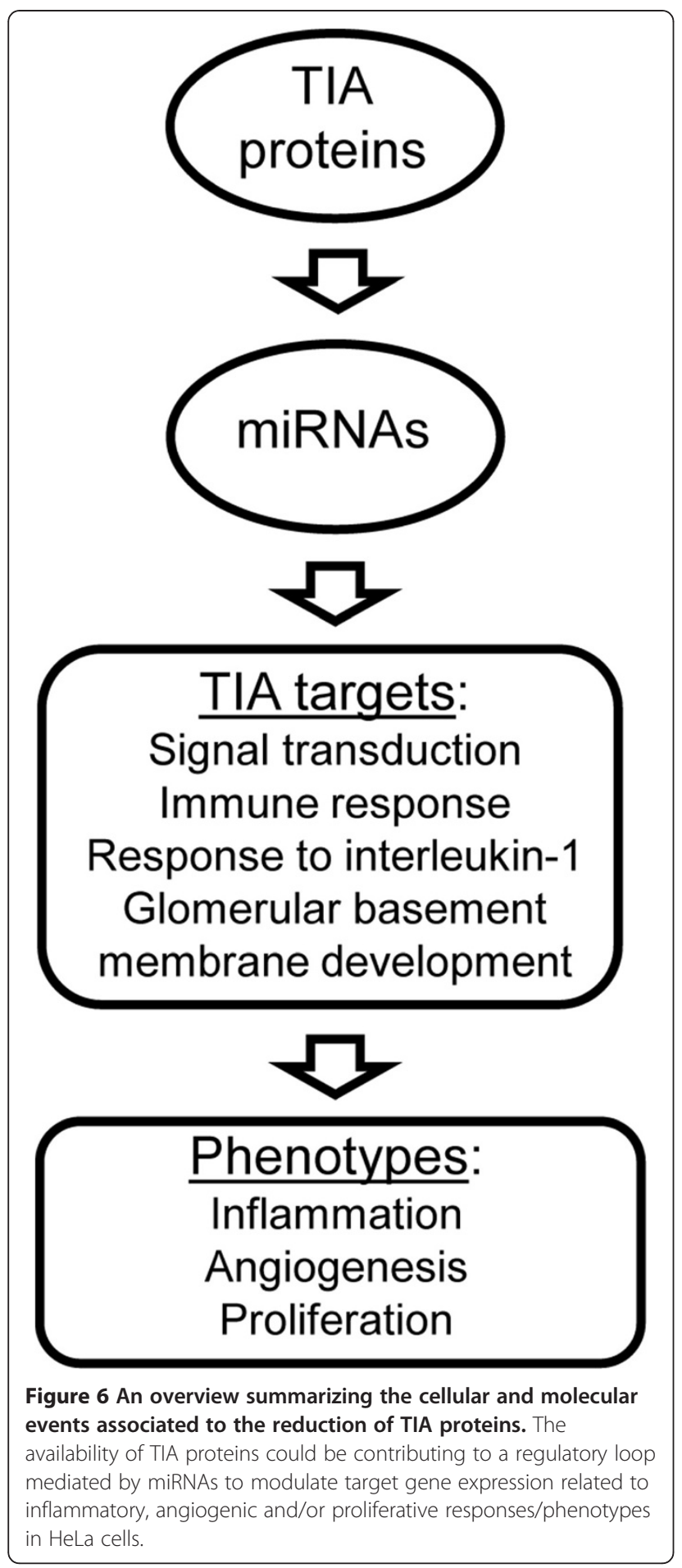

angiogenesis [54]. In addition, miR-371-5p is increased in gastric cancer [55] and miR-373 functions as an oncogene in hepatocellular carcinoma given that is a new regulator of protein phosphatase 6 [56], an repressor of the large tumor suppressor homolog 2 [57] and promotes tumor invasion and metastasis in testis cancer $[58,59]$. Further, both miRNA-210 and miRNA-373 participate in the gene expression control of DNA repair in hypoxic stress [60]. miRNA-492 and miRNA-498 are highly expressed and regulate metastatic functions in hepatoblastoma, rectal cancer, adenocarcinoma and retinoblastoma [61-64]. In addition, miR-503 is induced in angiogenesis, down-regulates CUGBP1 and modulates metastatic function in hepatocellular cancer cell [65-68]. miRNA-572 has been involved in chronic lymphocytic leukaemia via targeting anti-apoptotic genes [69,70]. miRNA-586 is up-regulated in colorectal cancer [71]. miRNA-615-3p dysregulates CDKN2A, NF2 and JUN in malignant mesothelioma [72] and enhances the phagocytic capacity of splenic macrophages [73]. miRNA-625 promotes invasion and metastasis of gastric cancer by targeting ILK [74]. miR-629 is associated to lung cancer by targeting NBS1 [75]. miRNA-638 and miR-658 are up-regulated in cell transformation and human gastric cancer [76,77]. In addition, other miRNAs show a great potential as activators of cell proliferation/transformation phenotypes; for example miRNA663 functions as an oncogene promoting tumorigenesis by targeting p21(WAF1/CIP1), VEGF, JunB, JunD and TGFB1 genes [78-80] and plays also a role in inflammatory response of endothelial cells [81]. miRNA 671 regulates CD44 inducing metastasis by regulating extracellular matrix functions [82] as well as miRNA-dependent gene silencing involving Ago2-mediated cleavage of a circular antisense RNA [83]. miRNA-744 up-regulates Cyclin B1 expression [37] and down-regulates Transforming Growth Factor Beta-1 expression [84]. On the other hand, other miRNAs identified in our study have bipolar features and putatively antagonistic behaviours as opposite regulators acting either positively or negatively under specific biological programmes. In this regards, there are at least 2 miRNAs showing functions to repress proliferation, angiogenesis and transformation phenotypes. This is the case of miRNA-483-5p, which suppresses the proliferation of glioma cells via directly targeting ERK1 [85] and angiogenesis in vitro by targeting serum response factor [86]. However, microRNA-483-5p and miRNA-195 have been identified as predictors of poor prognosis in adrenocortical cancer [87]. miR-125a-3p is down-regulated in non-small cell lung cancer, having inverse effects on invasion and migration of lung cancer cells [88]. This miRNA is a potent prognostic marker in gastric cancer [89]. Collectively, the miRNA expression profiling identified in this study has important aftermath in tumorigenesis and could contribute/repress to the development of cell proliferation, angiogenesis, transformation phenotypes, because individual miRNAs are associated with diagnosis, prognosis and treatment efficacy linked to the biology of human tumors. Therefore, these miRNAs can target to oncogenes or tumor suppressor genes (also they can even 
function themselves as such) and take part in the promotion or inhibition of tumorigenesis and cancer progression, thus being able to confer robustness to these pathological phenotypes.

In summary, our findings suggest that expression changes in individual miRNAs in TIA-depleted HeLa cells could directly or indirectly impact on biological processes and signaling pathways to favour cell phenotypes associated to the down-regulation of TIA proteins (Figure 6). Further, our observations suggest that some of the identified miRNAs are consistent with an adaptive response aimed at attenuating the inflammatory, angiogenic, and proliferative responses developed in TIA-protein absence. Therefore, cross talk between regulatory mechanisms that promote increased/reduced expression of miRNA-mediated genes may contribute to modify the relative expression levels of the mRNAs associated with TIA-lacking HeLa cells. Based on this integrative analysis, our results provide a prominent stand for future approaches aimed at characterizing the role of specific miRNAs in TIA-mediated gene expression regulation.

\section{Conclusions}

Gene expression profiling approaches have improved our understanding on how the human transcriptome dynamics orchestrates global responses at molecular level to answer to changing environmental challenges. Our study identifies a human miRNA collection that displays significant changes in the transient absence of TIA proteins in HeLa cells. The most prominent changes are linked to the up-regulation of miR-30b-3p, miR125a-3p, miR-193a-5p, miR-197-3p, miR-203a, miR-210, miR-371-5p, miR-373-5p, miR-483-5p, miR-492, miR-498, miR-503-5p, miR-572, miR586, miR-612, miR-615-3p, miR-623, miR-625-5p, miR-6295p, miR-638, miR-658, miR-663a, miR-671-5p, miR-769-3p and miR-744-5p. The integration of the identified miRNAs with the potential target genes and previous gene expression data under the same experimental conditions revealed enrichment of biological processes and signaling pathways controlling relevant members of the pathways associated to the oncogenesis. Down-regulation of these cellular components may contribute to establish the inflammatory, angiogenic, and proliferative responses previously described in TIA protein-lacking HeLa cells. Therefore, our results are consistent with the existence of regulatory networks that generate correlated expressions, commonly involving miRNAs $[33,90]$. This regulatory architecture may increase the fidelity of inhibition of the downstream components by acting on them redundantly. In other words, a transient loss of TIA proteins can be partially compensated for by the adaptive presence of specific miRNAs. Collectively, these findings suggest that TIA proteins can act as multifunctional regulators to provide a novel meeting point between the mechanisms for cross-talking among concerted post-transcriptional regulatory layers that coordinate complex cellular responses.

\section{Additional files}

Additional file 1: Summary of the miRNA array analyses. The following additional data are available in this file: 1) Correlation of Hy3 and Hy5 signals for the spike-in controls between slides. 2) Hy5 vs Hy3 scatter, MA and ratio distribution plots (before and after normalization) and Hy5 vs Hy3 scatter plot for the spike-in controls, for each independent experiments. 3) Statistical test implemented in the limma R.

Additional file 2: Update of miRNAs sequences previously

identified as miRPlus. The miRPlus sequences are licensed human

sequences (Exiqon, Denmark). Many of them are already annotated in the miRBase database version 18

Additional file 3: List of predicted potential target genes associated to up-regulated miRNAs in transiently TIA-depleted HeLa cells. Potential target genes of up-regulated miRNAs identified in TIA-deficient HeLa cells were predicted by TargetScan 5.2, PicTar-Vert and miRDB database downloaded using web-app miRBase (http://www.mirbase.org).

The Gene Ontology (GO) and Kyoto Encyclopedia of Genes and

Genomes (KEGG) database analyses were conducted using software programmes provided by GenCodis3 (http://genecodis.cnb.csic.es).

\begin{abstract}
Abbreviations
iCLIP: In vivo ultraviolet (UV)-crosslinking and immunoprecipitation to identify the RNA crosslinking sites of TIA1 and TIAR proteins; GO: Gene ontology; KEGG: Kyoto and encyclopedia of genes and genomes; siRNA: Small interfering RNA; TIA1: T-cell intracellular antigen 1; TIAR/ TIAL1: TIA1 related/like protein; UTR: Untranslated region of the eukaryotic mRNAs.
\end{abstract}

\section{Competing interests}

The authors declare that they have no competing interests.

\section{Authors' contributions}

JMI conceived the research and designed all experiments. CSJ, IC and JB carried out the experiments and analyzed the data presented in this paper. CSJ, IC, JB and JMI wrote the paper. All authors read and approved the final manuscript.

\section{Acknowledgements}

We are grateful to Jernej Ule for providing iCLIP data analysis of TIA proteins and Juan Carlos Oliveros for helping us with bioinformatics tools. This work was supported by grants from the Spanish Ministry of Innovation and Science through FEDER funds (BFU2008-00354 and BFU2011-29653). The CBMSO receives an institutional grant from Fundación Ramón Areces.

\section{Author details}

${ }^{1}$ Centro de Biología Molecular Severo Ochoa, Consejo Superior de Investigaciones Científicas, Universidad Autónoma de Madrid (CSIC/UAM), C/ Nicolás Cabrera 1, Cantoblanco, Madrid 28049, Spain. ${ }^{2}$ Current address: Programa de Biología de Sistemas, Centro Nacional de Biotecnología, Consejo Superior de Investigaciones Científicas, C/Darwin 3, Cantoblanco, Madrid 28049, Spain.

Received: 26 June 2012 Accepted: 4 February 2013

Published: 6 February 2013

\section{References}

1. McAlinden A, Liang L, Mukudai $Y$, Imamura T, Sandell $\sqcup$ : Nuclear protein TIA1 regulates COL2A1 alternative splicing and interacts with precursor mRNA and genomic DNA. J Biol Chem 2007, 282:24444-24454.

2. Suswam EA, Li YY, Mahtani H, King PH: Novel DNA-binding properties of the RNA-binding protein TIAR. Nucleic Acids Res 2005, 33:4507-4518.

3. Kim HS, Wilce MC, Yoga YM, Pendini NR, Gunzburg MJ, Cowieson NP, Wilson GM, Williams BR, Gorospe M, Wilce JA: Different modes of 
interaction by TIAR and HuR with target RNA and DNA. Nucleic Acids Res 2011, 39:1117-1130.

4. Das R, Yu J, Zhang Z, Gygi MP, Krainer AR, Gygi SP, Reed R: SR proteins function in coupling RNAP II transcription to pre-mRNA splicing. Mol Cell 2007, 26:867-881.

5. Del Gatto-Konczak F, Bourgeois CF, Le Guiner C, Kister L, Gesnel MC, Stevenin J, Breathnach R: The RNA-binding protein TIA1 is a novel mammalian splicing regulator acting through intron sequences adjacent to a 5 splice site. Mol Cell Biol 2000, 20:6287-6299.

6. Förch P, Puig O, Kedersha N, Martínez C, Granneman S, Séraphin B, Anderson P, Valcárcel J: The apoptosis-promoting factor TIA1 is a regulator of alternative pre-mRNA splicing. Mol Cell 2000, 6:1089-1098

7. Izquierdo JM, Majós N, Bonnal S, Martínez C, Castelo R, Guigó R, Bilbao D, Valcárcel J: Regulation of Fas alternative splicing by antagonistic effects of TIA1 and PTB on exon definition. Mol Cell 2005, 19:475-484

8. Wang Z, Kayikci M, Briese M, Zarnack K, Luscombe NM, Rot G, Zupan B, Curk T, Ule J: iCLIP predicts the dual splicing effects of TIA-RNA interactions. PLOS Biol 2010, 8:e1000530.

9. Yamasaki S, Stoecklin G, Kedersha N, Simarro M, Anderson P: T-cell intracellular antigen-1 (TIA1)-induced translational silencing promotes the decay of selected mRNAs. J Biol Chem 2007, 282:30070-30077.

10. Reyes R, Alcalde J, Izquierdo JM: Depletion of T-cell intracellular antigen (TIA)-proteins promotes cell proliferation. Genome Biol 2009, 10:R87.

11. López De Silanes I, Galbán S, Martindale JL, Yang X, Mazan-Mamczarz K, Indig FE, Falco G, Zhan M, Gorospe M: Identification and functional outcome of mRNAs associated with RNA-binding protein TIA1. Mol Cell Biol 2005, 25:9520-9531.

12. Mazan-Mamczarz K, Lal A, Martindale JL, Kawai T, Gorospe M: Translational repression by RNA-binding protein TIAR. Mol Cell Biol 2006, 26:2716-2727.

13. Kim HS, Kuwano Y, Zhan M, Pullmann R Jr, Mazan-Mamczarz K, Li H, Kedersha N, Anderson P, Wilce MC, Gorospe M, Wilce JA: Elucidation of a C-rich signature motif in target mRNAs of RNA-binding protein TIAR. Mol Cell Biol 2007, 27:6806-6817.

14. Liao B, Hu Y, Brewer G: Competitive binding of AUF1 and TIAR to MYC mRNA controls its translation. Nat Struct Mol Biol 2007, 14:511-518.

15. Damgaard CK, Lykke-Andersen J: Translational coregulation of 5/TOP mRNAs by TIA-1 and TIAR. Genes Dev 2011, 25:2057-2068.

16. Piecyk M, Wax S, Beck AR, Kedersha N, Gupta M, Maritim B, Chen S, Gueydan C, Kruys $V$, Streuli M, Anderson P: TIA1 is a translational silencer that selectively regulates the expression of TNF-alpha. EMBO J 2000, 19:4154-4163.

17. Beck AR, Miller JJ, Anderson P, Streuli M: RNA-binding protein TIAR is essential for primordial germ cell development. Proc Natl Acad Sci 1998, 95:2331-2336.

18. Kharraz Y, Salmand PA, Camus A, Auriol J, Gueydan C, Kruys V, Morello D: Impaired embryonic development in mice overexpressing the RNAbinding protein TIAR. PLoS One 2010, 5:e11352.

19. Bartel DP: MicroRNAs: target recognition and regulatory functions. Cell 2009, 136:215-233.

20. Smyth GK, Speed TP: Normalization of cDNA microarray data. Methods 2003, 31:265-273

21. Bolstad BM, Irizarry RA, Astrand M, Speed TP: A comparison of normalization methods for high density oligonucleotide array data based on bias and variance. Bioinformatics 2003, 19:185-193.

22. Smyth GK: Linear models and empirical bayes methods for assessing differential expression in microarray experiments. In statistical applications in genetics and molecular biology 2004. Volume 3. Number 1. Article 3. http://www.bepress.com/ sagmb/vol3/iss1/art3.

23. Benjamini $Y$, Hochberg $Y$ : Controlling the false discovery rate: a practical and powerful approach to multiple testing. J R Statist Soc B 1995, 57:289.

24. Oliveros JC: FIESTA at BioinfoGP. An interactive server for analyzing DNA microarray experiments with replicates. http://bioinfogp.cnb.csic.es/tools/FIESTA.

25. Lewis BP, Burge CB, Bartel DP: Conserved Seed Pairing, Often Flanked by Adenosines, Indicates that Thousands of Human Genes are MicroRNA Targets. Cell 2005, 120:15-20.

26. Krek A, Grün D, Poy MN, Wolf R, Rosenberg L, Epstein EJ, MacMenamin P, da Piedade I, Gunsalus KC, Stoffel M, Rajewsky N: Combinatorial microRNA target predictions. Nat Genet 2005, 37:495-500.

27. Wang $X$, El Naqa IM: Prediction of both conserved and nonconserved microRNA targets in animals. Bioinformatics 2008, 24:325-332.

28. Wang $X$ : miRDB: a microRNA target prediction and functional annotation database with a wiki interface. RNA 2008, 14:1012-1017.
29. Kozomara A, Griffiths-Jones S: miRBase: integrating microRNA annotation and deep-sequencing data. Nucleic Acids Res 2011, 39:D152-D157.

30. Carmona-Saez P, Chagoyen M, Tirado F, Carazo JM, Pascual-Montano A: GENECODIS: a web-based tool for finding significant concurrent annotations in gene lists. Genome Biol 2007, 8:R3.

31. Nogales-Cadenas R, Carmona-Saez P, Vazquez M, Vicente C, Yang X, Tirado F, Carazo JM, Pascual-Montano A: GeneCoDis: interpreting gene lists through enrichment analysis and integration of diverse biological information. Nucleic Acids Res 2009, 37:W317-W322.

32. Smoot M, Ono K, Ruscheinski J, Wang P-L, Ideker T: Cytoscape 2.8: new features for data integration and network visualization. Bioinformatics 2011, 27:431-432.

33. Friedman RC, Farh KK, Burge CB, Bartel DP: Most mammalian mRNAs are conserved targets of microRNAs. Genome Res 2009, 19:92-105.

34. Guo H, Ingolia NT, Weissman JS, Bartel DP: Mammalian microRNAs predominantly act to decrease target mRNA levels. Nature 2010, 466:835-840.

35. Ebert MS, Sharp PA: Roles for microRNAs in conferring robustness to biological processes. Cell 2012, 149:515-524.

36. Krol J, Loedige I, Fillipowicz W: The widespread regulation of microRNA biogenesis, function and decay. Nat Rev Genet 2010, 11:597-610.

37. Huang V, Place RF, Portnoy V, Wang J, Qi Z, Jia Z, Yu A, Shuman M, Yu J, L LC: Upregulation of Cyclin B1 by miRNA and its implications in cancer. Nucleic Acids Res 2012, 40:1695-1707.

38. Hiopoulos D, Hirsch HA, Struhl K: An epigenetic switch involving NFkappaB, Lin28, Let-3 MicroRNA, and IL6 links inflammation to cell transformation. Cell 2009, 139:693-706.

39. Mangan S, Alon U: Structure and function of the feed-forward loop network motif. Proc Natl Acad Sci USA 2003, 10:11980-11985.

40. Bridge G, Monteiro R, Henderson S, Emuss V, Lagos D, Georgopoulou D, Patient $R$, Boshoff $C$ : The microRNA-30 family targets DLL4 to modulate endothelial cell behavior during angiogenesis. Blood 2012, in press.

41. Quintavalle C, Donnarumma E, laboni M, Roscigno G, Garofalo M, Romano G, Fiore D, De Marinis P, Croce CM, Condorelli G: Effect of miR-21 and miR30b/c on TRAIL-induced apoptosis in glioma cells. Oncogene 2012, doi:10.1038/onc.2012.410

42. Shao C, Yu Y, Yu L, Pei Y, Feng Q, Chu F, Fang Z, Zhou Y: Amplification and up-regulation of microRNA-30b in oral squamous cell cancers. Arch Oral Biol 2012, 57:1012-1017.

43. Yang Y, Zhou L, Lu L, Wang L, Li X, Jiang P, Chan LK, Zhang T, Yu J, Kwong J, Cheung TH, Chung T, Mak K, Sun H, Wang H: A novel miR-193a-5p-YY1$\mathrm{APC}$ regulatory axis in human endometrioid endometrial adenocarcinoma. Oncogene 2012, doi:10.1038/onc.2012.360. Aug 20.

44. Moes M, Le Béchec A, Crespo I, Laurini C, Halavatyi A, Vetter G, Del Sol A Friederich E: A novel network integrating a miRNA-203/SNAI1 feedback loop which regulates epithelial to mesenchymal transition. PLOS One 2012, 7:e35440.

45. Moffatt CE, Lamont RJ: Porphyromonas gingivalis induction of microRNA203 expression controls suppressor of cytokine signaling 3 in gingival epithelial cells. Infect Immun 2011, 79:2632-2637.

46. Kelly TJ, Souza AL, Clish CB, Puigserver P: A hypoxia-induced positive feedback loop promotes hypoxia-inducible factor 1alpha stability through miR-210 suppression of glycerol-3-phosphate dehydrogenase 1-like. Mol Cell Biol 2011, 31:2696-2706.

47. Noman MZ, Buart S, Romero P, Ketari S, Janji B, Mari B, Mami-Chouaib F, Chouaib S: Hypoxia-inducible miR-210 regulates the susceptibility of tumor cells to lysis by cytotoxic T cells. Cancer Res 2012, 72:4629-4641.

48. Yoshioka Y, Kosaka N, Ochiya T, Kato T: Micromanaging iron homeostasis: hypoxia-inducible miR-210 suppresses iron homeostasis-related proteins. J Biol Chem 2012, 287:34110-34119.

49. Favaro E, Ramachandran A, McCormick R, Gee H, Blancher C, Crosby M, Devlin C, Blick C, Buffa F, Li JL, Vojnovic B, Pires Das Neves R, Glazer P, Iborra F, Ivan M, Ragoussis J, Harris AL: MicroRNA-210 regulates mitochondrial free radical response to hypoxia and krebs cycle in cancer cells by targeting iron sulfur cluster protein ISCU. PLOS One 2010, 26:e10345.

50. Chen Z, Li Y, Zhang H, Huang P, Luthra R: Hypoxia-regulated microRNA210 modulates mitochondrial function and decreases ISCU and COX10 expression. Oncogene 2010, 29:4362-4368.

51. Tsuchiya S, Fujiwara T, Sato F, Shimada Y, Tanaka E, Sakai Y, Shimizu K, Tsujimoto G: MicroRNA-210 regulates cancer cell proliferation through targeting fibroblast growth factor receptor-like 1 (FGFRL1). J Biol Chem 2011, 286:420-428 
52. Gou D, Ramchandran R, Peng X, Yao L, Kang K, Sarkar J, Wang Z, Zhou G, Raj JU: miR-210 has an anti-apoptotic effect in pulmonary artery smooth muscle cells during hypoxia. Am J Physiol Lung Cell Mol Physiol, in press.

53. Hong L, Yang J, Han Y, Lu Q, Cao J, Syed L: High expression of miR-210 predicts poor survival in patients with breast cancer: a meta-analysis. Gene 2012, 507:135-138.

54. Lou YL, Guo F, Liu F, Gao FL, Zhang PQ, Niu X, Guo SC, Yin JH, Wang Y, Deng ZF: miR-210 activates notch signaling pathway in angiogenesis induced by cerebral ischemia. Mol Cell Biochem, in press.

55. Liu P, Wilson MJ: miR-520c and miR-373 upregulate MMP9 expression by targeting mTOR and SIRT1, and activate the Ras/Raf/MEK/Erk signaling pathway and NF-kB factor in human fibrosarcoma cells. J Cell Physiol 2012, 227:867-876

56. Wu N, Liu X, Xu X, Fan X, Liu M, Li X, Zhong Q, Tang H: MicroRNA-373, a new regulator of protein phosphatase 6 , functions as an oncogene in hepatocellular carcinoma. FEBS J 2011, 278:2044-2054

57. Lee KH, Goan YG, Hsiao M, Lee CH, Jian SH, Lin JT, Chen YL, Lu PJ: MicroRNA-373 (miR-373) post-transcriptionally regulates large tumor suppressor, homolog 2 (LATS2) and stimulates proliferation in human esophageal cancer. Exp Cell Res 2009, 315:2529-2538.

58. Voorhoeve PM, le Sage C, Schrier M, Gillis AJ, Stoop H, Nagel R, Liu YP, van Duijse J, Drost J, Griekspoor A, Zlotorynski E, Yabuta N, De Vita G, Nojima H, Looijenga LH, Agami R: A genetic screen implicates miRNA-372 and miRNA-373 as oncogenes in testicular germ cell tumors. Cell 2006, 124:1169-1181.

59. Huang Q, Gumireddy K, Schrier M, le Sage C, Nagel R, Nair S, Egan DA, Li A, Huang G, Klein-Szanto AJ, Gimotty PA, Katsaros D, Coukos G, Zhang L, Puré E, Agami R: The microRNAs miR-373 and miR-520c promote tumour invasion and metastasis. Nat Cell Biol 2008, 10:202-210.

60. Crosby ME, Kulshreshtha R, Ivan M, Glazer PM: MicroRNA regulation of DNA repair gene expression in hypoxic stress. Cancer Res 2009, 69:1221-1229.

61. von Frowein J, Pagel P, Kappler R, von Schweinitz D, Roscher A, Schmid I: MicroRNA-492 is processed from the keratin 19 gene and up-regulated in metastatic hepatoblastoma. Hepatology 2011, 53:833-842.

62. Gaedcke J, Grade M, Camps J, Søkilde R, Kaczkowski B, Schetter AJ Difilippantonio MJ, Harris CC, Ghadimi BM, Møller S, Beissbarth T, Ried T, Litman $\mathrm{T}$ : The rectal cancer microRNAome - microRNA expression in rectal cancer and matched normal mucosa. Clin Cancer Res 2012, 18:4919-4930.

63. Schultz NA, Werner J, Willenbrock H, Roslind A, Giese N, Horn T, Wøjdemann M, Johansen JS: MicroRNA expression profiles associated with pancreatic adenocarcinoma and ampullary adenocarcinoma. Mod Pathol, in press.

64. Schepeler T, Reinert JT, Ostenfeld MS, Christensen LL, Silahtaroglu AN, Dyrskjøt L, Wiuf C, Sørensen FJ, Kruhøffer M, Laurberg S, Kauppinen S, Ørntoft TF, Andersen CL: Diagnostic and prognostic microRNAs in stage II colon cancer. Cancer Res 2008, 68:6416-6424.

65. Caporali A, Meloni M, Völlenkle C, Bonci D, Sala-Newby GB, Addis R, Spinetti G, Losa S, Masson R, Baker AH, Agami R, le Sage C, Condorelli G, Madeddu P, Martelli F, Emanueli C: Deregulation of microRNA-503 contributes to diabetes mellitus-induced impairment of endothelial function and reparative angiogenesis after limb ischemia. Circulation 2011, 123:282-291.

66. Zhou J, Wang W: Analysis of microRNA expression profiling identifies microRNA-503 regulates metastatic function in hepatocellular cancer cell. J Surg Oncol 2011, 104:278-283.

67. Cui YH, Xiao L, Rao JN, Zou T, Liu L, Chen Y, Turner DJ, Gorospe M, Wang $J Y$ : miR-503 represses CUG-binding protein 1 translation by recruiting CUGBP1 mRNA to processing bodies. Mol Biol Cell 2012, 23:151-162.

68. Caporali A, Emanueli C: MicroRNA-503 and the extended microRNA-16 family in angiogenesis. Trends Cardiovasc Med 2011, 21:162-166.

69. Zhu DX, Zhu W, Fang C, Fan L, Zou ZJ, Wang YH, Liu P, Hong M, Miao KR, Liu P, Xu W, Li JY: miR-181a/b significantly enhances drug sensitivity in chronic lymphocytic leukemia cells via targeting multiple anti-apoptosis genes. Carcinogenesis 2012, 33:1294-1301

70. Xiao W, Bao ZX, Zhang CY, Zhang XY, Shi LJ, Zhou ZT, Jiang WW: Upregulation of miR-31* is negatively associated with recurrent/newly formed oral leukoplakia. PLoS One 2012, 7:e38648.

71. Cummins JM, He Y, Leary RJ, Pagliarini R, Diaz LA Jr, Sjoblom T, Barad O, Bentwich Z, Szafranska AE, Labourier E, Raymond CK, Roberts BS, Juhl H, Kinzler KW, Vogelstein B, Velculescu VE: The colorectal microRNAome. Proc Natl Acad Sci 2006, 103:3687-3692.

72. Guled M, Lahti L, Lindholm PM, Salmenkivi K, Bagwan I, Nicholson AG, Knuutila S: CDKN2A, NF2, And JUN are dysregulated among other genes by miRNAs in malignant mesothelioma. A miRNA microarray analysis. Genes Chromosomes Cancer 2009, 48:615-623.

73. Jiang A, Zhang S, Li Z, Liang R, Ren S, Li J, Pu Y, Yang J: miR-615-3p promotes the phagocytic capacity of splenic macrophages by targeting ligand-dependent nuclear receptor corepressor in cirrhosis-related portal hypertension. Exp Biol Med 2011, 236:672-680.

74. Wang M, Li C, Nie H, Lv X, Qu Y, Yu B, Su L, Li J, Chen X, Ju J, Yu Y, Yan M, Gu Q, Zhu Z, Liu B: Down-regulated miR-625 suppresses invasion and metastasis of gastric cancer by targeting ILK. FEBS Lett 2012, 586:2382-2388.

75. Yang L, Li Y, Cheng M, Huang D, Zheng J, Liu B, Ling X, Li Q, Zhang X, Ji W, Zhou $Y$, Lu J: A functional polymorphism at microRNA-629-binding site in the 3/-untranslated region of NBS1 gene confers an increased risk of lung cancer in Southern and Eastern Chinese population. Carcinogenesis 2012, 33:338-347.

76. Li D, Wang Q, Liu C, Duan H, Zeng X, Zhang B, Li X, Zhao J, Tang S, Li Z, Xing X, Yang P, Chen L, Zeng J, Zhu X, Zhang S, Zhang Z, Ma L, He Z, Wang E, Xiao Y, Zheng Y, Chen W: Aberrant expression of miR-638 contributes to benzo(a)pyrene-induced human cell transformation. Toxicol Sci 2012, 125:382-391.

77. Guo J, Miao Y, Xiao B, Huan R, Jiang Z, Meng D, Wang Y: Differential expression of microRNA species in human gastric cancer versus nontumorous tissues. J Gastroenterol Hepatol 2009, 24:652-657.

78. Liu ZY, Zhang GL, Wang MM, Xiong YN, Cui HQ: MicroRNA-663 targets TGFB1 and regulates lung cancer proliferation. Asian Pac J Cancer Prev 2011, 12:2819-2823.

79. Tili E, Michaille JJ, Adair B, Alder H, Limagne E, Taccioli C, Ferracin M, Delmas D, Latruffe N, Croce CM: Resveratrol decreases the levels of miR-155 by upregulating miR-663, a microRNA targeting JunB and JunD. Carcinogenesis 2010, 31:1561-1566.

80. Yi C, Wang Q, Wang L, Huang Y, Li L, Liu L, Zhou X, Xie G, Kang T, Wang H, Zeng M, Ma J, Zeng $Y$, Yun JP: MiR-663, a microRNA targeting p21(WAF1/CIP1), promotes the proliferation and tumorigenesis of nasopharyngeal carcinoma. Oncogene 2012, 1:1-13.

81. Ni CW, Qiu H, Jo H: MicroRNA-663 upregulated by oscillatory shear stress plays a role in inflammatory response of endothelial cells. Am J Physiol Heart Circ Physiol 2011, 300:H1762-H1769.

82. Rutnam ZJ, Yang BB: The non-coding $3^{\prime}$ UTR of CD44 induces metastasis by regulating extracellular matrix functions. J Cell Sci 2012, 125:2075-2085.

83. Hansen TB, Wiklund ED, Bramsen JB, Villadsen SB, Statham AL, Clark SJ, Kjems J: miRNA-dependent gene silencing involving Ago2-mediated cleavage of a circular antisense RNA. EMBO J 2011, 30:4414-4422.

84. Martin J, Jenkins RH, Bennagi R, Krupa A, Phillips AO, Bowen T, Fraser DJ: Post-transcriptional regulation of transforming growth factor beta-1 by microRNA-744. PLoS One 2011, 6:e25044.

85. Wang L, Shi M, Hou S, Ding B, Liu L, Ji X, Zhang J, Deng Y: MiR-483-5p suppresses the proliferation of glioma cells via directly targeting ERK1. FEBS Lett 2012, 586:1312-1317.

86. Qiao Y, Ma N, Wang X, Hui Y, Li F, Xiang Y, Zhou J, Zou C, Jin J, Lv G, Jin H, Gao X: MiR-483-5p controls angiogenesis in vitro and targets serum response factor. FEBS Lett 2011, 585:3095-3100.

87. Soon PS, Tacon LJ, Gill AJ, Bambach CP, Sywak MS, Campbell PR, Yeh MW Wong SG, Clifton-Bligh RJ, Robinson BG, Sidhu SB: miR-195 and miR-483$5 p$ identified as predictors of poor prognosis in adrenocortical cancer. Clin Cancer Res 2009, 15:7684-7692.

88. Jiang L, Huang Q, Zhang S, Zhang Q, Chang J, Qiu X, Wang E: Hsa-miR$125 a-3 p$ and hsa-miR-125a-5p are downregulated in non-small cell lung cancer and have inverse effects on invasion and migration of lung cancer cells. BMC Cancer 2010, 10:318.

89. Hashiguchi $Y$, Nishida N, Mimori K, Sudo T, Tanaka F, Shibata K, Ishii H, Mochizuki H, Hase K, Doki Y, Mori M: Down-regulation of miR-125a-3p in human gastric cancer and its clinicopathological significance. Int J Oncol 2012, 40:1477-1482.

90. Friard O, Re A, Taverna D, De Bortoli M, Corá D, Circuits DB: a database of mixed microRNA/transcription factor feed-forward regulatory circuits in human and mouse. BMC Bioinforma 2010, 11:435.

doi:10.1186/1471-2199-14-4

Cite this article as: Sánchez-Jiménez et al:: Identification of a set of miRNAs differentially expressed in transiently TIA-depleted HeLa cells by genome-wide profiling. BMC Molecular Biology 2013 14:4. 